\title{
Sistema de Suplementação Alimentar para Bovinos de Corte em Pastejo. Validação
}

\author{
Rogério de Paula Lana ${ }^{1}$, Paulo Gomes Júnior ${ }^{2}$
}

\begin{abstract}
RESUMO - Objetivou-se com este trabalho a validação do programa de computador do Sistema Viçosa de Formulação de Rações, bem como testar o NRC 1996 de gado de corte, incluindo os níveis 1 (Sistema NRC) e 2 (Sistema Cornell), para bovinos de corte em pastejo. Os dados de ganho de peso preditos pelos programas, em função do peso corporal, dos grupos genéticos e da composição e do consumo de suplementos, durante o período da seca, foram comparados com os dados observados. O Sistema NRC, níveis 1 e 2 , subestimou o consumo de matéria seca em 12 e $13 \%$ e o ganho de peso, em 55 e 86\%, respectivamente, de 35 novilhos suplementados em pastagens durante o período da seca. Já o Sistema Viçosa, com menor margem de erro, superestimou o consumo em 5\% e subestimou o ganho em $11 \%$. Em um segundo ensaio de validação com um banco de dados de 25 experimentos, 74 tratamentos e 1230 animais, o Sistema Viçosa superestimou o ganho de peso, em função do consumo de energia (NDT), em 44\%. Apesar disto, o programa é adequado para ser utilizado nas formulações de suplementos alimentares para bovinos em crescimento em pastagens tropicais, uma vez que o consumo de alimentos e, conseqüentemente, o ganho de peso são altamente variáveis, devido à variação na disponibilidade e composição das pastagens, diversidades climáticas e genéticas dos animais.
\end{abstract}

Palavras-chave: banco de dados, consumo, ganho de peso, pastejo, uréia

\section{A System of Feed Supplementation for Beef Cattle under Grazing. Validation}

\begin{abstract}
This work had as objective to validate the computer program of Sistema Viçosa de Formulação de Rações, as well as the 1996 beef NRC, including levels 1 (NRC system) and 2 (Cornell System) for growing beef cattle under pastures. The data of daily gain predicted by the programs as a function of body weight, genetic groups and supplements composition and intake during the dry season were compared to the observed values. The levels 1 and 2 of NRC system underpredicted dry matter intake in 12 and $13 \%$ and daily gain in 55 and $86 \%$, respectively, of 35 supplemented steers in tropical pastures during the dry season. The Viçosa system overpredicted intake in 5\% and underpredicted daily gain in $11 \%$, with lower error. In a second validation assay with a data base of 25 experiments, 74 treatments and 1230 animals, the Viçosa system overpredicted the daily gain as a function of energy intake (TDN), in $44 \%$. In spite of that, the program is adequate to be utilized in formulation of feed supplements for growing bovines in tropical pastures, as feed intake and so, daily gain are highly variable, due to variation in pastures availability and composition, and diversity of climate and animal genetic.
\end{abstract}

Key Words: daily gain, database, intake, pasture, urea

\section{Introdução}

A produção de bovinos de corte no Brasil ocorre basicamente em sistema extensivo, com suplementação apenas de misturas minerais (Sousa, 1985). Nas regiões sudeste e centro-oeste, os animais alternam períodos de ganho e perda de peso, nas estações chuvosa e seca, respectivamente (Pereira, 1984). Em conseqüência do regime alimentar, o abate dos animais e o primeiro parto das fêmeas ocorrem, em média, de 4 a 4,5 anos (Fontes, 1995).

As categorias animais que mais sofrem com a redução no suprimento de nutrientes são os bovinos em fase de crescimento, pelos maiores requerimen- tos nutricionais, e vacas paridas, pela maior demanda de nutrientes para a produção de leite. A deficiência nutricional, além de reduzir o ganho de peso nos animais em crescimento e retardar a idade ao primeiro parto, aumenta o intervalo de partos, especialmente entre a primeira e segunda cria (Rodrigues \& Esteves, 1992).

Quando o valor nutritivo das plantas forrageiras cai com o avanço da sua maturação fisiológica, a suplementação pode ser utilizada para o fornecimento de quantidades controladas de proteína e energia, objetivando-se o desenvolvimento contínuo dos animais. Este procedimento propicia redução na idade de abate e aumento na taxa de desfrute. Um progra- 
ma de alimentação do rebanho é fundamental para prever as flutuações que podem ocorrer na oferta de forragem e pode determinar a quantidade estratégica de suplementação a ser fornecida para fazer frente a estas variações (Seiffert, 1982).

Em relação às diferentes raças, os animais de origem européia sofrem mais sob as condições adversas encontradas nas pastagens tropicais pois, devido à menor tolerância ao calor, se movimentam menos e aumentam a respiração, acarretando diminuição da ingestão de alimentos, aumento do consumo de água e redução dos processos produtivos, tais como: crescimento e produção de leite. Há tendência de os animais ficarem mais tempo em locais sombreados, aumentando a infestação de ecto e endo parasitos, além de já serem naturalmente menos tolerantes às infestações (Williamson \& Payne, 1975).

O Sistema Viçosa de Formulação de Rações (Lana, 2000) permite formular suplementos para bovinos em pastagens, levando em consideração os diferentes grupos genéticos e categorias animais. Os suplementos são utilizados para corrigir a deficiência dos nutrientes limitantes ou para permitir ganhos de peso mais elevados que aqueles em função da disponibilidade de nutrientes das pastagens. Para se obter em maiores desempenhos na pastagem, há necessidade de se utilizarem maiores quantidades de suplementos, devendo-se, portanto, levar em consideração a relação custo-benefício com a suplementação, como por exemplo o menor custo com alimentação por unidade de aumento no ganho de peso, redução da idade ao abate e aumento da fertilidade nas fêmeas.

Ainda não existem programas de computador para formulação de rações e suplementos alimentares para bovinos de corte em condições de pastagens, validado para as condições brasileiras. Este trabalho tem como objetivo validar o programa de computador do Sistema Viçosa de Formulação de Rações (Lana, 2000), bem como testar o NRC (1996) de gado de corte, incluindo os níveis 1 (Sistema NRC) e 2 (Sistema Cornell), para bovinos de corte sob regime de pastejo. Os dados de desempenho preditos pelos programas, em função do peso corporal, grupos genéticos e composição e consumo de suplementos durante o período da seca, foram comparados com os dados observados. Foram feitas, ainda, demonstrações de cálculos da relação custobenefício utilizando-se diferentes níveis e tipos de suplementos.

R. Bras. Zootec., v.31, n.1, p.451-459, 2002 (suplemento)

\section{Material e Métodos}

O trabalho foi desenvolvido no Departamento de Zootecnia da Universidade Federal de Viçosa, com base em dois bancos de dados. O primeiro consistiu de informações provenientes de uma tese de mestrado da Universidade Federal de Viçosa (Gomes Jr., 2000), em que foram utilizados 35 bezerros mestiços Holandês-Zebu, com $248 \mathrm{~kg}$ de peso corporal e 10 meses de idade, recebendo cinco tipos de suplementos na pastagem.

Os suplementos consistiram de apenas mistura mineral ou suplementos contendo farelo de trigo (50 a $82 \%$ ), uréia ( 8 a $10 \%$ ), sal comum (4\%), mistura mineral $(6 \%)$ e três fontes de proteína verdadeira substituindo o farelo de trigo (farelo de soja, 15\%; farelo de algodão, 30\%; e farelo de glúten de milho, $10 \%$ ). O consumo médio dos suplementos foram de $0,046,1,48,1,49,1,50$ e $1,48 \mathrm{~kg} /$ animal/dia, para a mistura mineral e os suplementos contendo farelo de soja, farelo de algodão, farelo de glúten de milho ou apenas farelo de trigo, respectivamente.

Foi feita a validação do programa de computador do NRC (1996), níveis 1 (Sistema NRC) e 2 (Sistema Cornell), e do programa Sistema Viçosa de Formulação de Rações (Lana, 2000), comparando-se o consumo e o ganho de peso preditos pelos sistemas com aqueles observados em condições experimentais.

Para predição do consumo de matéria seca, ganho de peso e conversão alimentar pelo programa do NRC (1996), utilizaram-se os dados de análises de alimentos apresentados na Tabela 1, referentes aos valores de matéria seca (MS), fibra em detergente neutro (FDN), lignina (Lig), proteína bruta (PB), proteína solúvel (PS) expressa na fração $\mathrm{A}+\mathrm{B} 1 \mathrm{da}$ $\mathrm{PB}$, nitrogênio não protéico (NNP), proteína insolúvel em detergente neutro e ácido (PIDN e PIDA), extrato etéreo (EE), nutrientes digestíveis totais (NDT) e cinzas (CZ).

Utilizaram-se, ainda, informações provenientes do banco de dados dos alimentos disponíveis no programa do NRC (1996) na validações, como os valores de fibra efetiva (FE), energia metabolizável (EM), energia líquida de mantença (ELm), energia líquida para ganho (ELg) e proteína degradável no rúmen (PDR) (Tabela 2) e as taxas de degradação das frações A, B1 e B2 dos carboidratos totais e das frações B1, B2 e B3 da proteína bruta (Tabela 3). Os dados de MS, FDN, PB e NDT apresentados na Tabela 1 e os de PDR apresentados na Tabela 2 
Tabela 1 - Características bromatológicas da forragem e dos concentrados fornecidos ao programa do NRC (1996), níveis 1 e 2

Table 1 - Chemical composition of forage and concentrate used in the program of NRC (1996), levels 1 and 2

\begin{tabular}{|c|c|c|c|c|c|c|c|c|c|c|}
\hline $\begin{array}{l}\text { Alimento } \\
\text { Food source }\end{array}$ & $\begin{array}{l}\mathrm{MS}^{1} \\
(\%) \\
D M \\
(\%)\end{array}$ & $\begin{array}{c}\mathrm{FDN}^{1} \\
(\% \mathrm{MS}) \\
N D F \\
(\% \quad D M)\end{array}$ & $\begin{array}{c}\text { Lig } \\
(\% \text { FDN }) \\
\text { Lig } \\
(\% N D F)\end{array}$ & $\begin{array}{c}\mathrm{PB}^{1} \\
(\% \mathrm{MS}) \\
C P \\
(\% D M)\end{array}$ & $\begin{array}{c}\mathrm{A}+\mathrm{B}_{1} \\
(\% \mathrm{~PB}) \\
A+B_{1} \\
(\% C P)\end{array}$ & $\begin{array}{c}\mathrm{NNP} \\
\left(\% \mathrm{PS}^{2}\right) \\
N P N \\
\left(\% S P^{2}\right)\end{array}$ & $\begin{array}{l}\mathrm{PIDN} \\
(\% \mathrm{~PB}) \\
N D I P \\
(\% C P)\end{array}$ & $\begin{array}{c}\text { PIDA } \\
(\% \mathrm{~PB}) \\
A D I P \\
(\% C P)\end{array}$ & $\begin{array}{c}\mathrm{EE} \\
(\% \mathrm{MS}) \\
E E \\
(\% D M)\end{array}$ & $\begin{array}{c}\mathrm{NDT}^{1} \\
(\% \mathrm{MS}) \\
T D N \\
(\% D M)\end{array}$ \\
\hline $\begin{array}{l}\text { Forragem } \\
\text { Forage }\end{array}$ & 55,5 & 79,0 & 8,05 & 3,96 & 37,0 & 80,0 & 28,0 & 12,3 & 1,5 & 48,0 \\
\hline $\begin{array}{l}\text { Farelo de soja } \\
\text { Soybean meal }\end{array}$ & 86,0 & 12,7 & 11,0 & 52,0 & 21,0 & 41,0 & 2,4 & 2,17 & 2,03 & 89,0 \\
\hline $\begin{array}{l}\text { Farelo de algodão } \\
\text { Cottonseed meal }\end{array}$ & 87,0 & 44,5 & 15,7 & 36,0 & 15,0 & 74,0 & 7,12 & 4,97 & 0,92 & 64,0 \\
\hline $\begin{array}{l}\text { Farelo de glúten } \\
\text { Corn gluten fed }\end{array}$ & 90,0 & 2,6 & 12,5 & 64,0 & 6,3 & 50,0 & 1,72 & 0,80 & 1,29 & 86,0 \\
\hline $\begin{array}{l}\text { Farelo de trigo } \\
\text { Wheat meaddlings }\end{array}$ & 86,0 & 47,7 & 10,3 & 16,0 & 42,0 & 45,0 & 24,25 & 3,21 & 4,48 & 74,0 \\
\hline $\begin{array}{l}\text { Uréia } \\
\text { Urea }\end{array}$ & 99,0 & 0,0 & 0,0 & 282,0 & 100 & 100,0 & 0,0 & 0,0 & 0,0 & 0,0 \\
\hline
\end{tabular}

foram também utilizados nas validações do Sistema Viçosa de Formulação de Rações.

O segundo banco de dados foi proveniente de vinte e cinco publicações sobre suplementação de bovinos em pastagens, nos anais das reuniões anuais da Sociedade Brasileira de Zootecnia, por M.F. Paulino e colaboradores, entre os anos de 1989 a 1995. Foram utilizadas informações de grande número de animais (1230), experimentos (25) e tratamen- tos (74) e feita a validação do Sistema Viçosa de Formulação de Rações (Lana, 2000).

Para estimar o ganho de peso dos animais pelo Sistema Viçosa, além das informações sobre o grupo genético e peso corporal dos animais, há necessidade de se obter informações sobre o consumo e a composição das pastagens, e do consumo e composição dos suplementos. A estimativa do consumo da pastagem foi feita subtraindo-se do consumo de matéria seca

Tabela 2 - Características bromatológicas da forragem e dos concentrados tabeladas pelo programa do NRC (1996) 1 Table 2 - Chemical composition of forage and concentrate from the tables of the program of NRC (1996) ${ }^{1}$

\begin{tabular}{|c|c|c|c|c|c|}
\hline $\begin{array}{l}\text { Alimento } \\
\text { Food source }\end{array}$ & $\begin{array}{l}\mathrm{FE}(\% \mathrm{FDN}) \\
E F(\% N D F)\end{array}$ & $\begin{array}{l}\mathrm{EM}(\mathrm{Mcal} / \mathrm{kg}) \\
M E(\text { Mcal/kg) }\end{array}$ & $\begin{array}{l}\mathrm{ELm}(\mathrm{Mcal} / \mathrm{kg}) \\
\operatorname{NEm}(\mathrm{Mcal} / \mathrm{kg})\end{array}$ & $\begin{array}{l}\operatorname{ELg}(\mathrm{Mcal} / \mathrm{kg}) \\
\mathrm{NEg}(\mathrm{Mcal} / \mathrm{kg})\end{array}$ & $\begin{array}{l}\mathrm{PDR}^{2}(\% \mathrm{~PB}) \\
R D P^{2}(\% C P)\end{array}$ \\
\hline $\begin{array}{l}\text { Forragem } \\
\text { Forage }\end{array}$ & 100,0 & 1,74 & 0,9 & 0,35 & 70,0 \\
\hline $\begin{array}{l}\text { Farelo de soja } \\
\text { Soybean meal }\end{array}$ & 23,0 & 3,22 & 2,21 & 1,52 & 65,0 \\
\hline $\begin{array}{l}\text { Farelo de algodão } \\
\text { Cottonseed meal }\end{array}$ & 36,0 & 2,31 & 1,44 & 0,86 & 57,0 \\
\hline $\begin{array}{l}\text { Farelo de glúten } \\
\text { Corn gluten meal }\end{array}$ & 36,0 & 3,11 & 2,12 & 1,45 & 38,0 \\
\hline $\begin{array}{l}\text { Farelo de trigo } \\
\text { Wheat meaddlings }\end{array}$ & 20,0 & 2,68 & 1,76 & 1,14 & 77,0 \\
\hline $\begin{array}{l}\text { Uréia } \\
\text { Urea }\end{array}$ & 0,0 & 0,0 & 0,0 & 0,0 & 100,0 \\
\hline
\end{tabular}

${ }^{1}$ Fibra efetiva (FE), energia metabolizável (EM), energia líquida de mantença (ELm), energia líquida para ganho (ELg) e proteína degradável no rúmen (PDR).

2 Dados também utilizados no Sistema Viçosa de Formulação de Rações (Lana, 2000).

${ }^{1}$ Effective fiber (EF), metabolizable energy (ME), net energy for maintenance (NEm), net energy for gain (NEg) and ruminal degradable protein (RDP).

${ }^{2}$ Data also used in the ration formulation system - Sistema Viçosa de Formulação de Rações (Lana, 2000). 
Tabela 3 - Taxas de degradação (\%/h) das frações $A, B_{1}$ e $B_{2}$ dos carboidratos totais e das frações $B_{1}$, $B_{2}$ e $B_{3}$ da proteína bruta da forragem e dos concentrados tabeladas pelo programa do NRC (1996)

Table 3 - Degradation rates $(\% / h)$ of fractions $A, B_{1}$ and $B_{2}$ of total carbohydrates and of fractions $B_{1}, B_{2}$ and $B_{3}$ of crude protein of the forage and concentrates from the tables of the program of NRC (1996)

\begin{tabular}{|c|c|c|c|c|c|c|}
\hline \multirow[t]{2}{*}{$\begin{array}{l}\text { Alimentos } \\
\text { Food sources }\end{array}$} & \multicolumn{3}{|c|}{$\begin{array}{l}\text { Carboidratos }(\% / \mathrm{h}) \\
\text { Carbohydrates }(\% / h)\end{array}$} & \multicolumn{3}{|c|}{$\begin{array}{c}\text { Proteínas }(\% / \mathrm{h}) \\
\text { Proteins }(\% / h)\end{array}$} \\
\hline & A & $\mathrm{B}_{1}$ & $\mathrm{~B}_{2}$ & $\mathrm{~B}_{1}$ & $\mathrm{~B}_{2}$ & $\mathrm{~B}_{3}$ \\
\hline $\begin{array}{l}\text { Forragem } \\
\text { Forage }\end{array}$ & 250 & 30 & 3 & 135 & 11 & 0,09 \\
\hline $\begin{array}{l}\text { Farelo de soja } \\
\text { Soybean meal }\end{array}$ & 300 & 45 & 6 & 230 & 11 & 0,20 \\
\hline $\begin{array}{l}\text { Farelo de algodão } \\
\text { Cottonseed meal }\end{array}$ & 300 & 25 & 3 & 175 & 8 & 0,25 \\
\hline $\begin{array}{l}\text { Farelo de glúten } \\
\text { Corn gluten meal }\end{array}$ & 300 & 50 & 5 & 150 & 4 & 0,08 \\
\hline $\begin{array}{l}\text { Farelo de trigo } \\
\text { Wheat meaddlings }\end{array}$ & 300 & 70 & 12 & 250 & 5,5 & 0,10 \\
\hline
\end{tabular}

total estimado por equações, o consumo de suplemento (Lana, 2000). Os valores da composição das pastagens no período da seca e dos suplementos foram obtidos de tabelas de composição de alimentos (Lana, 2000).

\section{Resultados e Discussão}

O Sistema NRC (1996), níveis 1 (Sistema NRC) e 2 (Sistema Cornell), subestimou o consumo de matéria seca em 12 e 13\% (Figura 1) e o ganho de peso em 55 e $86 \%$ (Figura 2), respectivamente, de 35 novilhos suplementados em pastagens tropicais durante o período da seca. O NRC (1996) apresenta na tabela 7-2, página 91 , validação das equações de consumo de pastagens de clima temperado por animais em crescimento (banco de dados de Alberta, Canadá), em que as mesmas subestimaram o consumo em 8,4 e 7,9\%, bem próximo do verificado acima para animais em pastagens tropicais.

Não foram encontradas validações do NRC (1996) para o ganho de peso de bovinos em pastagens. Num trabalho de validação do CNCPS, que faz parte do nível 2 do NRC (1996), o programa superestimou em $10 \%$ o ganho de peso de bovinos em pastagem temperada em função do consumo de energia metabolizável (Fox et al., 1995). Para bovinos em confinamento, o NRC (1984) subestimou em 4\% o consumo de matéria seca e em $12,4 \%$ o ganho de peso (Traxler et al., 1995), e o NRC (1996) subestimou a eficiência alimentar (ganho/consumo) em 13 e 23\%, pelos níveis 1 e 2 do mesmo (Lana et al., 1997).
No Brasil, Lanna et al. (1994a) verificaram que o CNCPS e o NRC (1984) subestimaram o consumo de matéria seca (121,8 e $126,7 \%$, respectivamente) de animais confinados recebendo bagaço de cana hidrolizado e subestimaram o ganho de peso em $7 \mathrm{e}$ $14 \%$, respectivamente. Em outro trabalho de validação de desempenho de zebuínos em crescimento pelos mesmos autores (Lanna et al., 1994b), o CNCPS e o NRC (1984) subestimaram o ganho de peso em 1 e $21 \%$, respectivamente.

Era de se esperar que o NRC (1996) subestimasse o ganho de peso dos animais em pastagens tropicais, uma vez que o mesmo subestimou o consumo de matéria seca, mas a subestimativa do ganho de peso foi muito alta (Figura 2). Por outro lado, o Sistema Viçosa superestimou o consumo em 5\% e subestimou o ganho de peso em 11\% (Figura 3) mostrando, nas condições deste experimento, ser adequado para se estimar o desempenho e fazer recomendações de nutrientes na formulação de suplementos alimentares para bovinos sob pastejo.

Com base no banco de dados com 1230 animais, proveniente de 25 experimentos de suplementação alimentar de bovinos em crescimento em regime de pastagens, e obtido de publicações encontradas nos anais da SBZ por M.F. Paulino e colaboradores, foi feita a segunda validação do Sistema Viçosa de Formulação de Rações (Lana, 2000). Neste ensaio, o Sistema Viçosa superestimou o ganho de peso em $44 \%$ em função do consumo de energia (NDT) (Figura 4a). As razões para esta superestimativa podem ser as seguintes: 

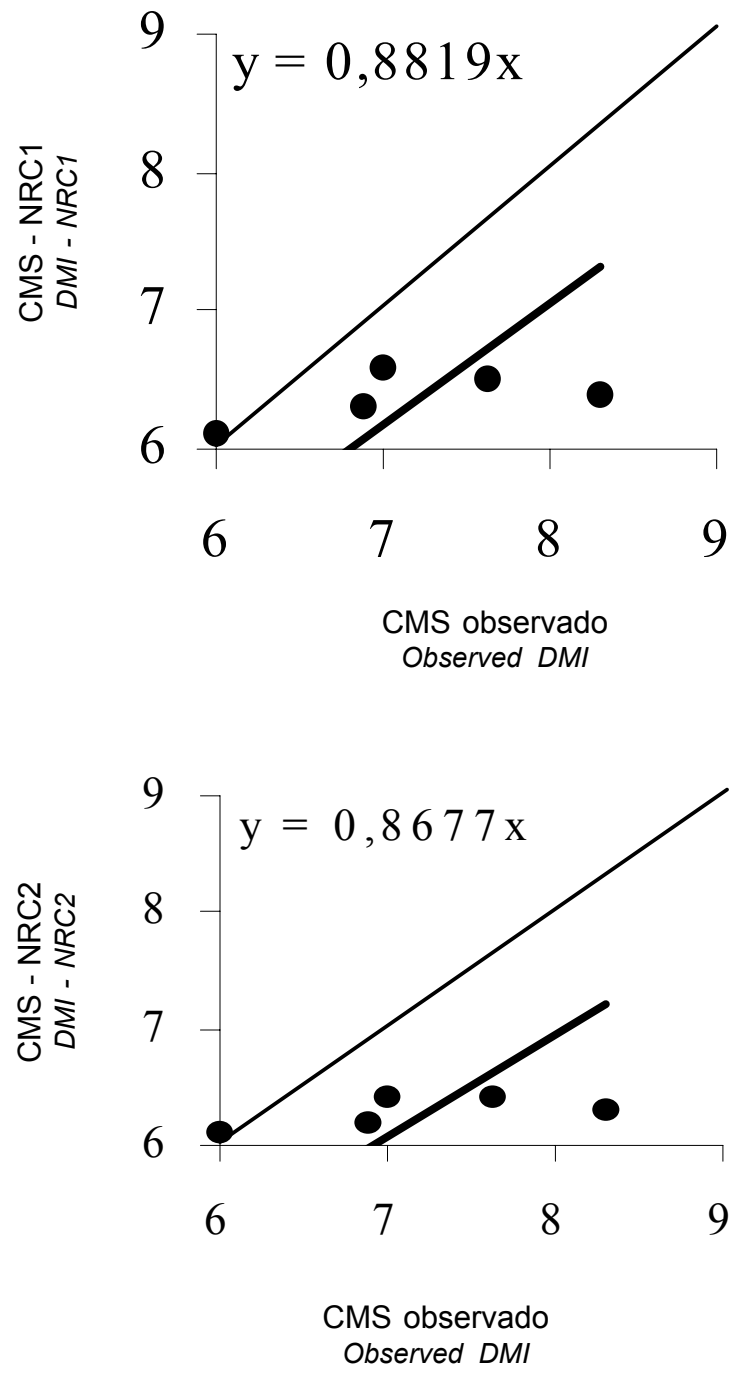

Figura 1 - Relação entre o consumo de matéria seca predito pelos níveis 1 e 2 do NRC (1996) e o consumo observado, em $\mathrm{kg} /$ animal/dia.

Figure 1 - Relation between the dry matter intake predicted by levels 1 and 2 of the NRC (1996) and the observed intake, in $\mathrm{kg} / \mathrm{animal} / \mathrm{day}$.

1) Alguns tratamentos não apresentaram proteína suficiente para o animal atingir o ganho de peso estimado em função do nível de energia (Figura 4b).

2) Superestimativa do consumo de matéria seca para bovinos em pastagens em condições tropicais, variando de 2,4 a 3,9\% do peso corporal (Figura 5).

3) Falta de informações sobre a composição (NDT e PB), disponibilidade e consumo das pastagens para se determinar o consumo de seus nutrientes.

4) Utilização do valor médio de NDT da pastagem de $50 \%$ no período da seca, conforme apresentado na tabela de composição de alimentos do Sistema Viçosa
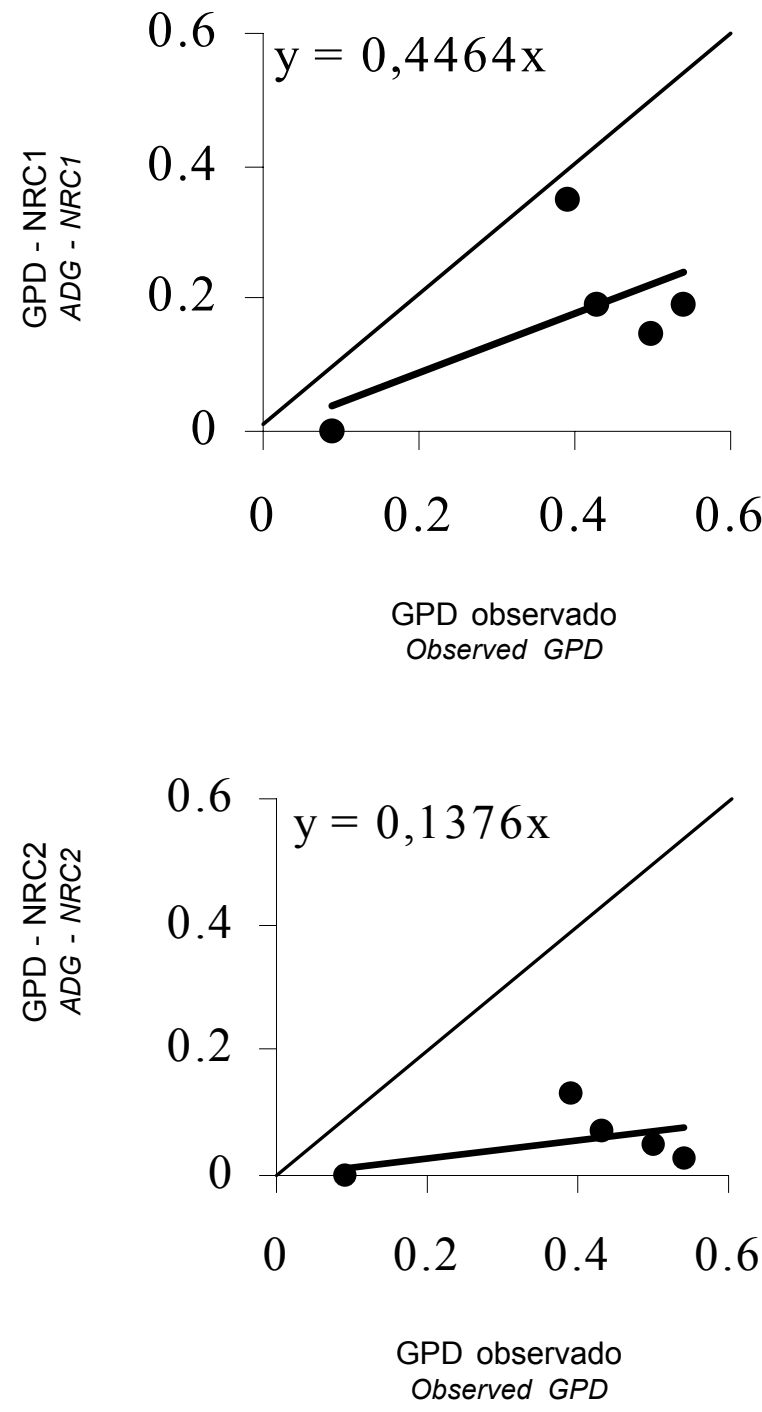

Figura 2 - Relação entre o ganho de peso predito pelos níveis 1 e 2 do NRC (1996), em função do consumo de energia metabolizável, e o ganho de peso observado, em kg/animal/dia.

Figure 2 - Relation between the daily gain predicted by levels 1 and 2 of the NRC (1996), as a function of metabolizable energy intake, and the observed daily gain, in $\mathrm{kg} / \mathrm{animal} / \mathrm{day}$.

de Formulação de Rações (Lana, 2000), que provavelmente foi alto, superestimando o ganho de peso.

No Brasil, o consumo de matéria seca pelos bovinos sob pastejo é mais baixo devido ao efeito de enchimento do trato gastrintestinal pelo volumoso, que é rico em fibra e de baixa digestibilidade. Portanto, há necessidade de se desenvolver equações de consumo de matéria seca para bovinos sob pastejo nas condições tropicais, bem como estimar o efeito associativo dos suplementos sobre o consumo das plantas forrageiras. Com base nas informações descritas anteriormente, além de informações brasileiras 

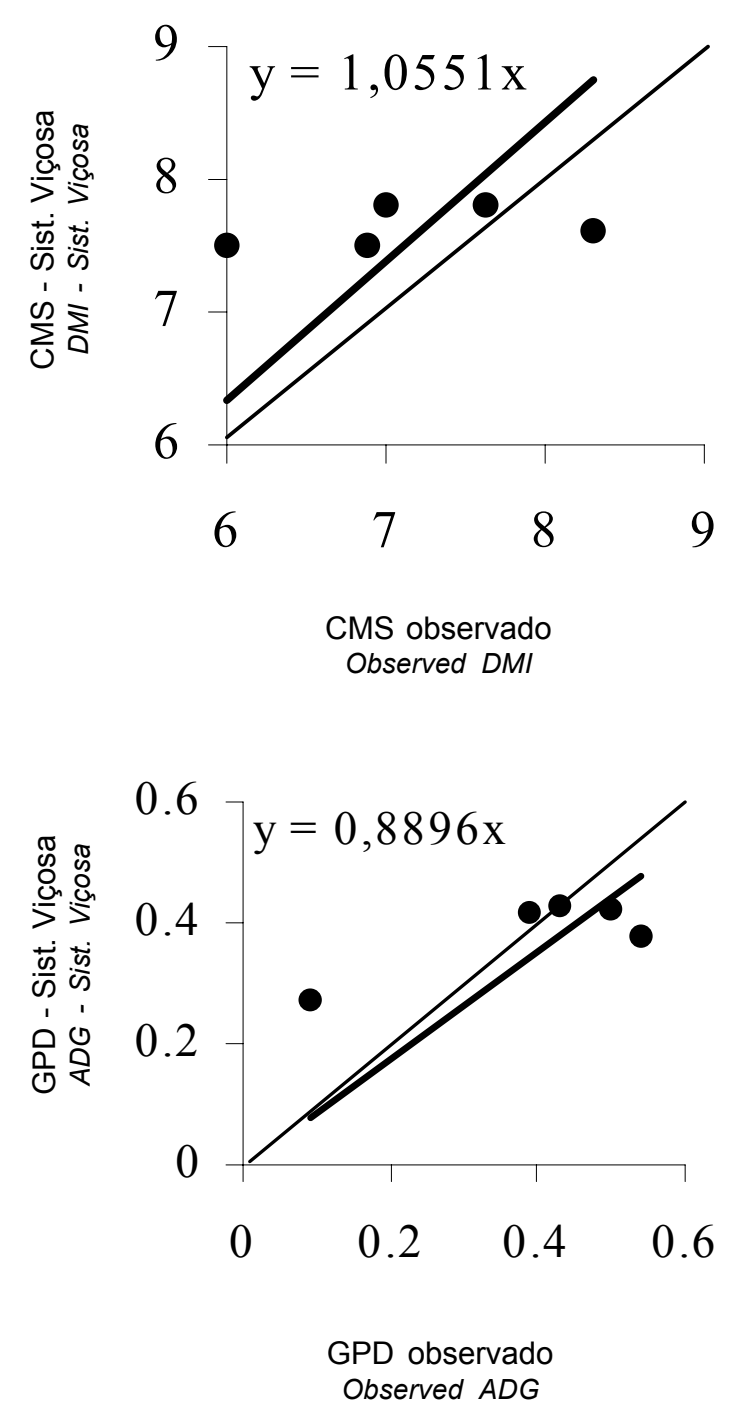

Figura 3 - Relações entre o consumo de matéria seca e ganho de peso em função do consumo de NDT, preditos pelo Sistema Viçosa de Formulação de Rações (Lana, 2000), e os valores observados, em $\mathrm{kg} / \mathrm{animal} / \mathrm{dia}$.

Figure 3 - Relation between the dry matter intake and daily gain as a function of TDN intake, predicted by the program Sistema Viçosa de Formulação de Rações (Lana, 2000), and the observed values, in kg/animal/day.

sobre exigências nutricionais dos animais, pode-se obter melhores predições do desempenho dos bovinos em pastagens tropicais.

Apesar de o erro de estimativa do ganho de peso ter sido bem superior ao primeiro ensaio de validação (44\% vs -11\%), ainda está abaixo daqueles observados pelo programa do NRC (1996), que foram de 55 e $86 \%$ (Figura 2). Em seguida, são apresentadas três equações de regressão utilizando o segundo banco de
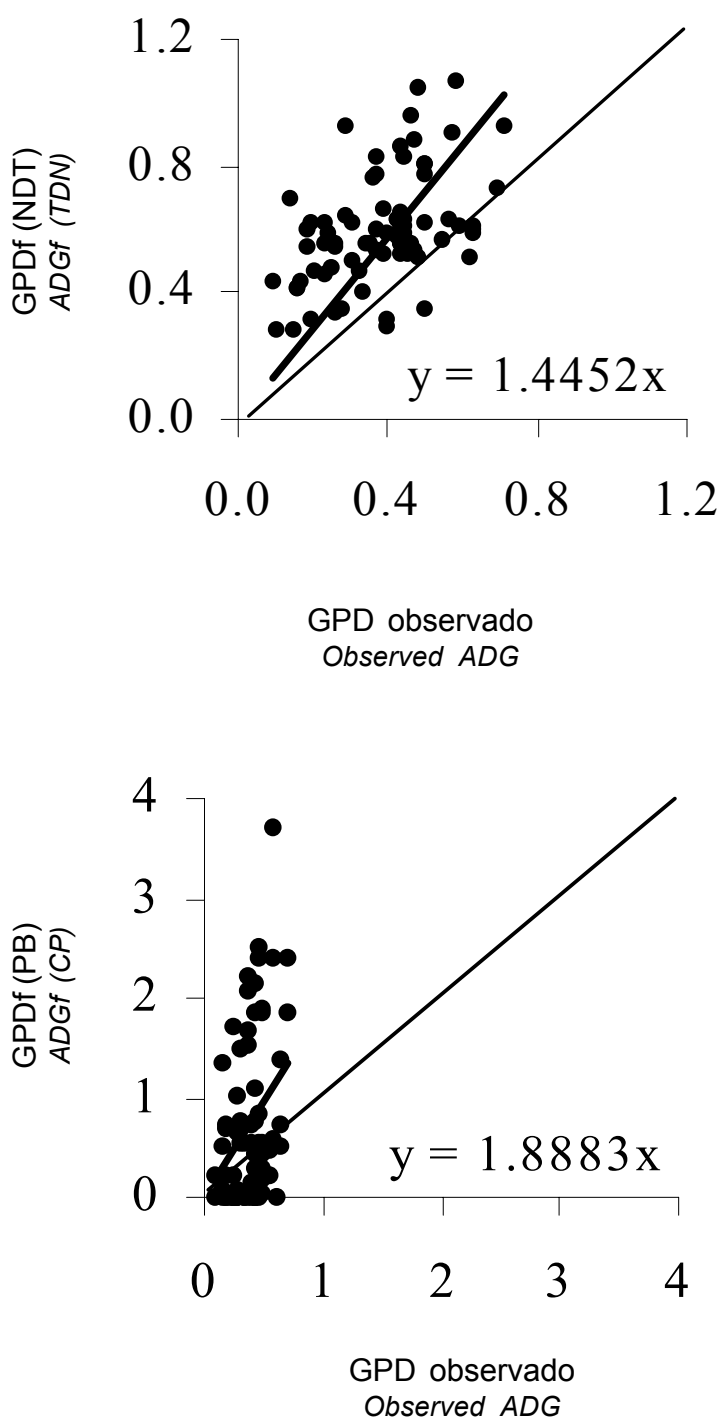

Figura 4 - Relações entre o ganho de peso em função do consumo de NDT ou PB, preditos pelo Sistema Viçosa de Formulação de Rações (Lana, 2000), e os valores observados, em $\mathrm{kg} / \mathrm{animal} / \mathrm{dia}$.

Figure 4 - Relation between the daily gain as a function of TDN or CP intake, predicted by the program Sistema Viçosa de Formulação de Rações (Lana, 2000), and the observed values, in $\mathrm{kg} / \mathrm{animal} / \mathrm{day}$.

dados: a primeira apresenta a relação entre o ganho de peso estimado em função do consumo de NDT e o ganho de peso observado; a segunda apresenta a regressão forçada através da origem, para se obter os erros de estimativa, conforme relatados anteriormente; e a terceira apresenta uma equação de regressão múltipla que melhor estima o ganho de peso observado: $\operatorname{GDPf}(\mathrm{NDT})=0,384+(0,566 *$ GDPobs $) \mathrm{r}^{2}=22,1 \%$ $\operatorname{GDPf}(\mathrm{NDT})=1,44 *$ GDPobs 
GDPobs $=0,223+(0,104 *$ raça $)+(0,0793 *$ Csupl $)$ - $(0,0281 * \% \mathrm{Ur}) \mathrm{r}^{2}=44,2 \%$

em que: GDPf(NDT) = estimativa do ganho de peso em função do consumo de NDT, em kg/animal/dia; GDPobs = ganho de peso observado, em kg/animal/ dia; raça $=1$ para nelore e 2 para mestiços europeuzebu; Csupl = consumo de suplemento alimentar, em $\mathrm{kg} / \mathrm{animal} / \mathrm{dia}$; e \% Ur = teor de uréia + sulfato de amônia no suplemento alimentar.

Verifica-se que a primeira equação explica apenas $22,1 \%$ da variabilidade dos dados de estimativas do ganho de peso dos animais em função dos ganhos de peso observados. Esta grande variação na estimativa do ganho de peso pode ser atribuída à alta variação no consumo de alimentos a que os animais estão sujeitos nas pastagens, conforme demonstram as tabelas 7.2 e 7.3 do NRC (1996) e também observada nas estimativas de consumo de matéria seca dos animais deste experimento (Figura 5). Uma vez que o ganho de peso está diretamente relacionado ao consumo de alimentos, variações sobre o consumo afetam diretamente o ganho de peso. Acrescenta-se a isto a grande variação da disponibilidade e composição das pastagens, que, por sua vez, são dependentes da fertilidade e umidade do solo, estação do ano, clima etc. A terceira equação foi apre-

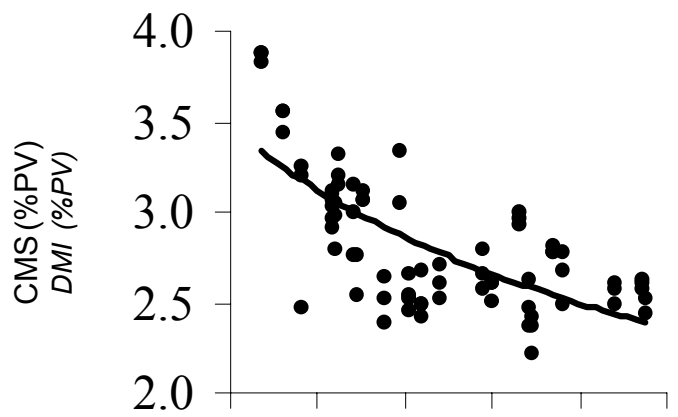

100150200250300350

$\mathrm{PV}(\mathrm{kg})$

$B W(\mathrm{~kg})$

Figura 5 - Consumo de matéria seca, em porcentagem do peso vivo dos animais experimentais, predito pelo Sistema Viçosa de Formulação de Rações (Lana, 2000), em função do peso corporal e composição da dieta.

Figure 5 - Dry matter intake, in percentage of body weight of the experimental animals, predicted by the program Sistema Viçosa de Formulação de Rações (Lana, 2000), as a function of body weight and diet composition. sentada como alternativa para se estimar o ganho de peso com maior precisão, permitindo, assim, explicar maior variabilidade dos dados.

Pelo exposto acima, em que o ganho de peso de bovinos em pastagens é altamente variável, uma superestimativa deste parâmetro em $44 \%$ é aceitável, podendo o Sistema Viçosa de Formulação de Rações ser recomendado para balancear a dieta dos animais. Com isto, pode-se fazer o balanceamento dos nutrientes (NDT, PB e minerais), evitando-se, assim, o fornecimento de excesso ou deficiência de nutrientes que possam prejudicar o desempenho dos animais e o custo de produção.

O banco de dados com os 1230 animais em pastagens consistiu principalmente de novilhas zebuínas e mestiças europeu-zebu, mas também de novilhos destes mesmos padrões genéticos. O peso vivo inicial variou de 130 a $340 \mathrm{~kg}$ e o consumo de suplementos de 0,2 a 4,0 kg/animal/dia. Foram feitas análises de correlações e regressões entre o ganho de peso (Tabela 4) ou consumo de suplementos (Tabela 5) e: peso à maturidade (peso aos $28 \%$ de gordura corporal), peso vivo, idade e consumos diários ( $\mathrm{kg} / \mathrm{animal} / \mathrm{dia})$ de suplemento alimentar, de uréia + sulfato de amônia, de NDT, de $\mathrm{PB}$ e de $\mathrm{PB}$ oriundo de fontes de proteína verdadeira no suplemento.

Os fatores que afetaram o ganho de peso dos animais em pastagens foram o porte corporal (peso à maturidade) e o suplemento alimentar (Tabela 4). Animais mestiços apresentaram maior ganho de peso que zebuínos, não havendo efeito de sexo sobre este parâmetro. Apesar do suplemento afetar positivamente o ganho de peso, os animais somente responderam com $0,101 \mathrm{~kg}$ de ganho de peso/animal/dia por cada $\mathrm{kg}$ de consumo de suplemento (Tabela 4); ou seja, a conversão alimentar foi de 10:1. Esta resposta foi também observada por Lana (2000), página 51, utilizando um outro banco de dados, onde o ganho de peso foi de $0,142 \mathrm{~kg}$ por $\mathrm{kg}$ de consumo de suplemento.

Os resultados apresentados demonstram que a suplementação com quantidade liberal de concentrado para bovinos em crescimento em pastagens pode ser antieconômica se o objetivo for a comercialização de animais para o abate. Para efeito de ilustração, considerando o custo de $1 \mathrm{~kg}$ de suplemento $=\mathrm{R} \$ 0,30$, e que o animal, ao consumir este suplemento, produzirá de 0,101 a $0,142 \mathrm{~kg}$ de GDP, o equivalente em reais de carcaça comercializável será $\mathrm{R} \$ 0,18$ $(((0,101+0,142) / 2) * 0,54 * 1 / 15 * 41)$, inferior ao custo 
Tabela 4 - Correlações e parâmetros das regressões lineares (intercepto = a, coeficiente $=\mathrm{b}$ ) entre o ganho de peso $(\mathrm{kg} / \mathrm{animal} /$ dia) e: peso à maturidade (peso aos $28 \%$ de gordura corporal), peso vivo (PV), idade e consumos diários de suplemento alimentar (Supl), de uréia + sulfato de amônia (Ur+SA), de nutrientes digestíveis (NDT), de proteína bruta (PB) e proteína bruta de fontes de proteína verdadeira (PBverd) no suplemento, em $\mathrm{kg} / \mathrm{animal} / \mathrm{dia}$

Table 4 - Correlations and parameters of linear regression (intercept $=a$, coefficient $=b$ ) between the daily gain ( $\mathrm{kg} / \mathrm{animal} / \mathrm{day})$ and: mature body weight (weight at $28 \%$ body fat; PV28\%G), live weight (PV), age (months) and daily intake of feed supplement (Supl), urea + ammonium sulphide $(U r+S A)$, total digestible nutrients (NDT), crude protein (PB) and crude protein from true protein sources (PBverd) in the supplement, in $\mathrm{kg} / \mathrm{animal} / \mathrm{day}$

\begin{tabular}{|c|c|c|c|c|c|c|c|c|}
\hline & \multirow[t]{2}{*}{$\begin{array}{l}\text { PV28\%G } \\
\quad(\mathrm{kg})^{\mathrm{a}}\end{array}$} & \multirow[t]{2}{*}{$\begin{array}{l}\text { PV } \\
(\mathrm{kg})\end{array}$} & \multirow[t]{2}{*}{$\begin{array}{l}\text { Idade (meses) } \\
\text { Age (months) }\end{array}$} & \multicolumn{4}{|c|}{$\begin{array}{l}\text { Consumos (kg/animal/dia) } \\
\text { Intakes (kg/animal/day) }\end{array}$} & \multirow[b]{2}{*}{ PBverd } \\
\hline & & & & Supl & $\mathrm{Ur}+\mathrm{SA}$ & NDT & PB & \\
\hline Correl -r & $0,33^{* *}$ & $0,21^{\mathrm{ns}}$ & $0,17^{\mathrm{ns}}$ & $0,57^{* * *}$ & $0,39^{* * *}$ & $0,58^{* * *}$ & $0,51^{* * *}$ & $0,56^{* * *}$ \\
\hline Interce-a & $-0,291$ & 0,276 & 0,279 & 0,219 & 0,293 & 0,214 & 0,252 & 0,239 \\
\hline Coefic-b & 0,0014 & 0,000484 & 0,0058 & 0,101 & 1,05 & 0,152 & 0,252 & 0,515 \\
\hline
\end{tabular}

a PV28\%G = Peso do animal com 28\% de gordura corporal (peso na maturidade). Eqüivale a 400, 450, 500 e $550 \mathrm{~kg}$ de peso corporal para zebuínos castrados e inteiros e mestiços europeu/zebu castrados e inteiros, respectivamente, e a 450 e $500 \mathrm{~kg}$ de peso corporal para novilhas zebuínas e mestiças europeu/zebu, respectivamente (Lana, 2000).

* *, * * * Significativo a 1 e $0,1 \%$ de probabilidade, respectivamente; ns Não-significativo $(P>0,05)$.

a $\quad P V 28 \% G=$ Animal weight at $28 \%$ of body fat (mature weight). It is equivalent to $400,450,500$ and $550 \mathrm{~kg}$ of body weight for zebu, steers and bulls, and crossbred european/zebu, steers and bulls, respectively, and to 450 and $500 \mathrm{~kg}$ of body weight for zebu and crossbred european/zebu heifers, respectively (Lana, 2000).

**, ** $\quad$ Significant at 1 and $0.1 \%$ probability, respectively; ${ }^{n s}$ Not significant $(P>05)$.

com suplementação. $\mathrm{O}$ valor 0,54 corresponde ao rendimento de carcaça, $1 / 15$ corresponde à conversão de $\mathrm{kg}$ de carcaça em arroba e 41 , ao custo da arroba de carcaça em reais.

A suplementação com uso de fontes de proteína verdadeira não foi tão desvantajosa quando comparada às fontes energéticas, mas ainda não foi a opção adequada. Considerando que $1 \mathrm{~kg}$ de farelo de soja custa $\mathrm{R} \$ 0,47$ e este propicia $0,23 \mathrm{~kg}$ de GDP $(1 * 0,45 * 0,515$; em que 0,45 corresponde a $\% / 100$ de $\mathrm{PB}$ e 0,515 , ao GDP/ kg PBverd consumida - Tabela 4), a venda da carcaça obtida resulta em $\mathrm{R} \$ 0,34(0,23 * 0,54 * 1 / 15 * 41)$, também não cobrindo o custo com suplementação.
A suplementação foi mais atrativa pelo aumento do ganho de peso em função do uso de uréia para cobrir a deficiência de nitrogênio das pastagens. Considerando que $1 \mathrm{~kg}$ da uréia custa $\mathrm{R} \$ 0,52$ e este irá propiciar $1,05 \mathrm{~kg}$ de GDP (Tabela 4 ), a venda da carcaça obtida resultará em $\mathrm{R} \$ 1,55\left(1,05 * 0,54 * 1 / 15^{*} 41\right)$, bem acima do custo com suplementação. Para a suplementação da uréia, o mais apropriado é o uso da mesma em suplementos de baixo consumo, conforme apresentado no Sistema Viçosa de Formulação de Rações, página 53 (Lana, 2000).

Os fatores que afetaram o consumo de suplemento dos animais em pastagens foram o porte corporal,

Tabela 5 - Correlações e parâmetros das regressões lineares (intercepto $=a$, coeficiente $=b$ ) entre o consumo de suplemento (kg/animal/dia) e: peso à maturidade (peso aos $28 \%$ de gordura corporal), peso vivo (PV), idade e conteúdos de uréia (\%Uréia) e mistura mineral (\%MM) no suplemento

Table 5 - Correlations and parameters of linear regression (intercept $=a$, coefficient $=b)$ between the supplement intake $(\mathrm{kg} /$ animal/day) and: mature body weight (weight at $28 \%$ body fat; $P V 28 \%$ G), live weight (PV), age (months) and urea (\%Uréia) and mineral (\%MM) content in the supplement

\begin{tabular}{|c|c|c|c|c|c|}
\hline & \multirow[t]{2}{*}{$\begin{array}{l}\text { PV28\%G } \\
\quad(\mathrm{kg})^{\mathrm{a}}\end{array}$} & \multirow[t]{2}{*}{$\begin{array}{l}\mathrm{PV} \\
(\mathrm{kg})\end{array}$} & \multirow[t]{2}{*}{$\begin{array}{l}\text { Idade (meses) } \\
\text { Age (months) }\end{array}$} & \multicolumn{2}{|c|}{$\begin{array}{l}\text { Suplemento } \\
\text { Supplement }\end{array}$} \\
\hline & & & & \%Uréia & $\% \mathrm{MM}$ \\
\hline Correlação -r & $0,36^{* *}$ & $0,30^{* *}$ & $0,52^{* * *}$ & $0,20^{\mathrm{ns}}$ & $0,02^{\mathrm{ns}}$ \\
\hline Intercepto-a & $-2,53$ & 0,737 & 0,078 & 0,991 & 1,54 \\
\hline Coeficiente-b & 0,00862 & 0,00399 & 0,115 & 0,162 & 0,0121 \\
\hline
\end{tabular}

a Ver rodapé da Tabela 9.

* *,${ }^{* * *}$ Significativo ao nível de 1 e $0,1 \%$ de probabilidade, respectivamente; ns Não-significativo $(P>0,05)$.

a See botton of Table 9 .

**, *** Significant at 1 and $0.1 \%$ probability, respectively; ${ }^{n s}$ Not significant $(P>.05)$. 
peso vivo e idade (Tabela 5). Os animais mestiços consumiram mais suplemento, explicando em parte $o$ maior ganho de peso observado em relação aos zebuínos. Os teores de uréia e os de mistura mineral nos suplementos não influenciaram os consumos dos mesmos, uma vez que o banco de dados utilizado nesta análise apresenta em sua maioria valores pouco variáveis de uréia $(5,2+1,6 \%)$ e mistura mineral $(3,8+1,0 \%)$.

\section{Conclusões}

O Sistema Viçosa de Formulação de Rações (Lana, 2000) é um programa adequado para ser utilizado nas formulações de suplementos alimentares para bovinos em crescimento em pastagens tropicais, apesar das dificuldades em se predizer com acurácia o desempenho dos animais. As dificuldades ocorrem em razão do consumo de alimentos e, conseqüentemente, do ganho de peso serem altamente variáveis, devido às alterações nas disponibilidades e composição das pastagens, diversidade genética dos animais e diversidade climática. Há necessidade de se desenvolver equações de consumo de matéria seca por bovinos em pastagens tropicais, monitoramento da disponibilidade e composição das plantas forrageiras, bem como estimar o efeito associativo dos suplementos sobre o seu consumo. Com base nestas informações e nas de exigências nutricionais dos animais nas condições brasileiras, há possibilidade de se obter melhores predições do desempenho dos bovinos sob sistema de pastagens.

\section{Literatura Citada}

FONTES, C.A.A. Composição corporal, exigências líquidas de nutrientes para ganho de peso e desempenho produtivo de animais zebuínos e mestiços europeu-zebu. In: PEREIRA, J.C. (Ed.) SIMPÓSIO INTERNACIONAL SOBRE EXIGÊNCIAS NUTRICIONAIS DE RUMINANTES, 1995, Viçosa. Anais... Viçosa, MG: Universidade Federal de Viçosa, 1995. p.419-456.

FOX, D.G.; BARRY, M.C.; PITT, R.E. et al. Application of the Cornell Net Carbohydrate and protein model for cattle consuming forages. Journal of Animal Science, v.73, p.267-277, 1995.

GOMES Jr., P. Composição químico-bromatológica da Brachiaria decumbens e desempenho de novilhos em recria suplementados durante a época seca. Viçosa, MG: Universidade Federal de Viçosa, 2000. 63p. Dissertação (Mestrado em Zootecnia) - Universidade Federal de Viçosa, 2000.
LANA, R.P. Sistema Viçosa de formulação de rações. Viçosa, MG: Universidade Federal de Viçosa, 2000. 60p.

LANA, R.P.; FOX, D.G.; RUSSELL, J.B. et al. Influence of monensin on Holstein steers fed high-concentrate diets containing soybean meal or urea. Journal of Animal Science, v.75, p.2571-2579, 1997.

LANNA, D.P.D.; BOIN, C.; FOX, D.G. Utilização do CNCPS para estimativa do desempenho animal e do valor nutricional do bagaço de cana tratado a pressão e vapor. In: REUNIÃO ANUAL DA SOCIEDADE BRASILEIRA DE ZOOTECNIA, 31., 1994, Maringá. Anais... Maringá: Sociedade Brasileira de Zootecnia, 1994a, p.478.

LANNA, D.P.D.; BOIN, C.; FOX, D.G. Validação do CNCPS e do NRC (1984) para estimativa dos requerimentos nutricionais e desempenho de zebuínos em crescimento. In: REUNIÃO ANUAL DA SOCIEDADE BRASILEIRA DE ZOOTECNIA, 31., 1994, Maringá. Anais... Maringá: Sociedade Brasileira de Zootecnia, 1994b. p.480.

NATIONAL RESEARCH COUNCIL - NRC. Nutrient requirements of beef cattle. 6.ed. Washington, D.C.: National Academy Press, 1984.

NATIONAL RESEARCH COUNCIL - NRC. Nutrient requirements of beef cattle. 7.ed. Washington, D.C.: National Academy Press, 1996. 242p.

PEREIRA, J.C. Confinamento de bovinos. Viçosa, MG: Universidade Federal de Viçosa, 1984. 20p. (Informe teórico, v.5, n.48)

RODRIGUES, A.A.; ESTEVES, S.N. Cana-de-açúcar e uréia para alimentação de bovinos na época da seca. São Carlos: Empresa Brasileira de Pesquisa Agropecuária - UEPAE, 1992. 30p. (Circular Técnica, 6).

SEIFFERT, N.F. Alimentação do rebanho de corte em época seca. Informe Agropecuário, v.8, n.89, p.20-27, 1982.

SOUSA, J.C. Formulação de misturas minerais para bovinos de corte. Campo Grande: Empresa Brasileira de Pesquisa Agropecuária - CNPGC, 1985. 26p. (Circular Técnica, 19).

TRAXLER, M.J.; FOX, D.G.; PERRY, T.C. et al. Influence of roughage and grain processing in high-concentrate diets on the performance of long-fed Holstein steers. Journal of Animal Science, v.73, p.1888-1900, 1995.

WILLIAMSON, G.; PAYNE, W.J.A. La ganadería en regiones tropicales. Barcelona: Blume, 1975. p.468.
Recebido em: 26/04/01 Aceito em: 17/09/01 